\title{
O PÁSSARO E AS ESTRELAS: PARA EMANCI- PAR A IMAGINAÇÃO SOBRE A JUSTIÇA
}

ANA PAULA FRIGHETTO PEREIRA UNIVERSIDADE FEDERAL DE SANTA MARIA SANTA MARIA, RIO GRANDE DO SUL, BRASIL ANAFRIGHETTO97@GMAIL.COM

ISABEL FOLETTO CURVELLO UNIVERSIDADE FEDERAL DE SANTA MARIA SANTA MARIA, RIO GRANDE DO SUL, BRASIL ISABELFOLETTO@GMAIL.COM

LETICIA BLANK NETTO UNIVERSIDADE FEDERAL DE SANTA MARIA SANTA MARIA, RIO GRANDE DO SUL, BRASIL LETICIABLANK@HOTMAIL.COM

MARÍLIA DE NARDIN BUDÓ UNIVERSIDADE FEDERAL DE SANTA MARIA SANTA MARIA, RIO GRANDE DO SUL, BRASIL MARILIADB@YAHOO.COM.BR

MATEUS RECH GRACIANO DOS SANTOS UNIVERSIDADE FEDERAL DE SANTA MARIA SANTA MARIA, RIO GRANDE DO SUL, BRASIL MATEUSG.RECH@HOTMAIL.COM 
MICAL ALEXIA ABRANTES MORAES

UNIVERSIDADE FEDERAL DE SANTA MARIA SANTA MARIA, RIO GRANDE DO SUL, BRASIL MICALALEXIA@GMAIL.COM

PABLO DOMINGUES DE MELLO UNIVERSIDADE FEDERAL DE SANTA MARIA SANTA MARIA, RIO GRANDE DO SUL, BRASIL PABLODOMINGUESMELLO@GMAIL.COM

PRISCILLA SILVA UNIVERSIDADE FEDERAL DE SANTA MARIA SANTA MARIA, RIO GRANDE DO SUL, BRASIL PRISCILLASILVA1095@GMAIL.COM

RAFAELA BOGADO MELCHIORS UNIVERSIDADE FEDERAL DE SANTA MARIA SANTA MARIA, RIO GRANDE DO SUL, BRASIL RAFAELAMELCHIORS@HOTMAIL.COM

THAIS BONATO GOMES UNIVERSIDADE FEDERAL DE SANTA MARIA SANTA MARIA, RIO GRANDE DO SUL, BRASIL THAISBONATOG@GMAIL.COM

YNGRID ALGARVE VIZZOTTO UNIVERSIDADE FEDERAL DE SANTA MARIA SANTA MARIA, RIO GRANDE DO SUL, BRASIL YNGRIDALGARVE@HOTMAIL.COM 


\section{O PÁSSARO E AS ESTRELAS: PARA EMANCIPAR A IMAGINAÇÃO SOBRE A JUSTIÇA}

Resumo: Neste trabalho, buscamos enfrentar o tema da insuficiência do sistema de justiça criminal para lidar com tragédias como a da boate Kiss. Analisamos a limitação da categoria "crime"; a operacionalidade real do sistema penal; a invisibilização das vítimas. Destacamos a necessidade de a justiça que mira o futuro passar pela memória e pela verdade sobre o passado, através da centralidade do diálogo, a partir da escuta das necessidades das vítimas.

Palavras-chave: Boate Kiss; vítimas; dano social; abolicionismo penal; justiça restaurativa

\section{EL PÁJARO Y LAS ESTRELLAS: PARA EMANCIPAR LA IMAGINACIÓN SOBRE LA JUSTICIA}

Resumen: En este trabajo, buscamos enfrentar el tema de la insuficiencia del sistema de justicia criminal para hacer frente a tragedias como la de la discoteca Kiss. Analizamos la limitación de la categoría "crimen"; la operabilidad real del sistema penal; la invisibilización de las víctimas. Destacamos la necesidad de la justicia que mira el futuro pasar por la memoria y por la verdad sobre el pasado, a través de la centralidad del diálogo, a partir de la escucha de las necesidades de las víctimas.

Palabras-clave: Discoteca Kiss; víctimas; daño social; abolicionismo penal; justicia restaurativa

\section{THE BIRD AND THE STARS: EMANCIPATING THE IMAGINATION ON JUSTICE}

Abstract: In this work, we try to address the issue of the insufficiency of the criminal justice system to deal with tragedies such as the Kiss nightclub. We analyze the limitation of the category "crime"; the actual operation of the penal system; the invisibility of the victims. We emphasize the need of the justice that looks to the future to pass through memory and truth about the past, through the centrality of dialogue, from listening to the needs of the victims.

Keywords: Kiss nightclub; victims; social harm; penal abolitionism; restorative justice 


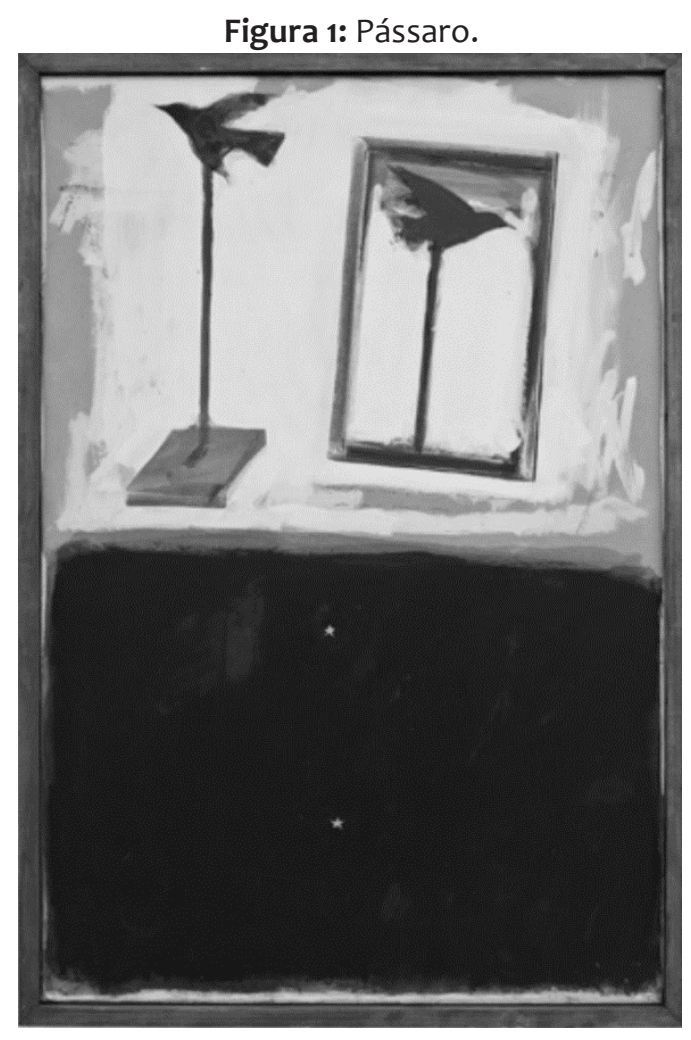

Fonte: Gravura de Evandro Carlos Jardim.

\section{INTRODUÇÃO}

Acontecimentos trágicos provocam profundas feridas, difíceis de expressar com palavras. A madrugada de 27 de janeiro de 2013 marcou a história da cidade de Santa Maria, coração do Rio Grande do Sul, com o incêndio da boate Kiss, que vitimou 242 jovens, deixando os rastros de perplexidade, luto e inquietude até hoje visíveis, especialmente, para os sobreviventes e familiares dos envolvidos diretamente na tragédia. "Nunca uma nuvem foi tão nefasta. Nem as tempestades mais mórbidas e elétricas desejam sua companhia. Seguirá sozinha, avulsa, página arrancada de um mapa" (CARPINEJAR, 2013).

A Rua dos Andradas, no centro da cidade, amanheceu tomada por gritos e afogada em lágrimas. Aos poucos, os estrondos foram substituídos pelo silêncio angustiante. Familiares e amigos, nas primeiras horas da tragédia, ficavam à espera de qualquer indício que significasse a ausência de algum ente querido daquela situação; antes pensar que ele já havia saído, ido dormir na casa de alguém ou estaria procurando um local para lanchar.

Naquela ocasião, não fora o uso de drogas ou o excesso de álcool constantes inimigos da juventude nas preocupações familiares - que levara a vida de mais de 200 jovens. Essa perda foi desenhada pelas irregularidades 
técnicas do estabelecimento somadas ao uso indevido de aparentemente insignificantes fogos de artificio.

No último dia do mesmo mês, em meio ao luto e à angústia, os anseios daqueles que ficaram ganhavam novo abrigo. Acomodavam-se no interior das capas rosas de um processo criminal. Ganhavam um número. As lágrimas se convertiam em páginas. Mais precisamente, quase vinte mil delas. $O$ processo havia sido distribuído, e a saga judicializada tinha início. A partir de então, era o Poder Judiciário, oficialmente, o guardião do conflito.

Durante a tramitação, inúmeras vigílias e manifestações foram criadas por amigos e familiares, para lembrar-nos de que a morte é mais do que papéis e que a dor sentida é, sobretudo, real e ultrapassa qualquer narrativa a ser contada por aqueles que não a vivenciaram. Essa ausência completa de palavras se torna ainda mais evidente quando a tentativa de narrar se concretiza nas letras estampadas e depositadas na frieza daquelas pilhas de incalculáveis documentos a abarrotarem o cartório da vara criminal.

A intermediária cidade gaúcha, conhecida por abrigar inúmeros estudantes universitários, foi palco de uma perda coletiva: pais, filhos, netos, namorados, colegas, conhecidos... Independentemente do vínculo, o sentimento de luto tomou conta da região e chocou o mundo. Tratar desse assunto, a fim de reafirmar o compromisso para que isso não volte a ocorrer, é um trabalho árduo, que exige sensibilidade. Para além de uma série de questionamentos técnicos e jurídicos que possam vir a ser observados a partir do caso, trata-se de um tema humano, que envolve os sentimentos mais genuínos e profundos daqueles que permaneceram e, também, a dignidade e memória dos que partiram.

Este trabalho busca enfrentar essa questão, com todas as dificuldades que são evidentes ao tratarmos de um caso como o da boate Kiss. Mais especificamente, tem por objetivo compreender as maneiras como as vítimas são tratados pelo sistema de justiça criminal, e que tipo de solução este sistema está fadado a oferecer a elas. O texto está dividido em três partes. Na primeira, analisamos a insuficiência da categoria "crime" para lidar com tragédias, e a correlata incapacidade de produção de uma resposta digna às vítimas; na segunda parte, analisamos criticamente a operacionalidade real do sistema penal expondo a injustiça e seletividade inscritas em seu DNA; na quarta parte, contrapomos a lógica retributiva do sistema de justiça criminal e a invisibilização das vítimas neste modelo à lógica restaurativa; por fim tratamos sobre a importância da memória e da verdade para a prevenção 
de novas tragédias.

\section{APENAS PASTAS DE CAPA ROSA? A REDUÇÃO DO SOFRIMENTO À MEDIDA DA CATEGORIA CRIME}

Muitas atrocidades cometidas durante o último século foram praticamente invisíveis para a ciência que, em suas origens, buscava estudar os crimes e os criminosos (MORRISON, 2014). Desde os delitos dos Estados, como as torturas e assassinatos durante regimes políticos autoritários e democráticos, até as catástrofes ecológicas causadas por grandes empresas, o fato é que elas escaparam e escapam da definição jurídica de crime, até mesmo por terem como autores agentes desconhecidos do direito penal e da criminologia clássica. Ciente dessa incapacidade de resposta a danos sociais de grandes proporções, não é de hoje que a criminologia tenta se desvincular do objeto que seu próprio nome indica: o conceito de crime enquanto realidade ontológica, aquele - majoritariamente patrimonial - praticado por um indivíduo "delinquente" (HILLYARD; TOMBS, 2015).

Afastar-se do conceito de crime conforme a definição do sistema penal implicaria em finalmente esta disciplina alcançar os grandes danos, ante os quais aquele mesmo sistema mantém-se - por razões estruturais - inerte. Para repensar esse objeto para além daquela definição, o conceito de dano social surge com sua característica amplitude de definição, um exemplo de uma dessas sensações que as palavras não conseguem traduzir.

A dificuldade de conceituação do dano social como tentativa de abstração de uma materialidade de dor e sofrimento reais traz, por um lado, algo de positivo: isso torna razoável que a construção de tal conceito seja enraizada nas vozes daquelas pessoas que testemunham diretamente essa dor, ou seja, as perspectivas de suas vítimas (NATALI; BUDÓ, 2018; COLOGNESE, 2017; SILVEIRA, 2018). De qualquer forma, algumas diretrizes podem ser estabelecidas para a definição do que seria o dano social.

Conforme defendem Tombs e Hillyard (2013, p.184-185), o dano social abarca desde os danos físicos até problemas psicológicos, de insegurança cultural e financeiros. Essa amplitude permite trazer ao foco da análise não apenas as condutas individuais geralmente percebidas no senso comum como criminosas, mas também as condutas dos Estados e das grandes corporações, uma vez que, apesar de afetarem significativamente a vida das pessoas em razão dos danos massivos que causam, são desconsideradas 
pelo sistema penal e raramente são criminalizadas (BERNAL et al. 2017). A defesa de uma teoria do dano social se justifica pela insuficiência daquele conceito de crime ligado ao direito penal e às leis penais para que se possa definir o objeto da criminologia.

Insuficiência que passa diretamente pelo fato de que reduz o que deveria ser um espectro amplo de acontecimentos e de suas consequências ao conhecido binômio crime-pena, simplesmente excluindo o dano (HILLYARD; TOMBS, 2013, p.178). A principal consequência dessa redução é a restrição de todas as possibilidades de lidar com aqueles danos àquilo que o próprio direito penal prevê: uma eventual pena ou responsabilização pecuniária, que, de modo algum, é capaz de exprimir uma resposta suficiente às vítimas. Para as vítimas, os danos se perpetuam na memória, nas dores em relação às quais nem a "justiça" da pena, nem a reparação econômica representam soluções efetivas.

Recentemente, o Brasil se viu diante do maior crime ambiental de sua história. O rompimento da barragem de rejeitos de minérios construída e operada por uma empresa mineradora multinacional, a BHP e a SAMARCO, varreu uma comunidade em uma literal avalanche de lama, que percorreu uma longa distância, destruindo ecossistemas inteiros até chegar ao mar. Além das quase 20 mortes dos moradores que ali viviam, a avalanche da lama destruiu um rio, estilos de vida e toda uma memória (COLOGNESE, 2017).

Numa pequena comunidade como a de Bento Rodrigues, envolta ao Rio Doce, com moradores cuja subsistência dependia ou do emprego na empresa ou da agricultura familiar e da pesca realizadas na própria região, a total destruição da paisagem a jusante, em razão da sobreposição de uma camada de lama espessa com baixo teor de nutrientes e carbono orgânico, torna inviável a recuperação de um estilo de vida (MILANEZ, 2015, p. 61). Para essas pessoas, a dor é tão grande quanto o desafio que consiste em ressignificar uma existência.

Não à toa que, passados 3 anos da "tragédia", fora - literalmente - das discussões jurídicas que envolvem a questão, os moradores de Bento Rodrigues tenham sido acometidos por uma crise generalizada de depressão. O transtorno de estresse pós-traumático (TEPT) é ainda mais sério, sendo que, segundo estudo, o risco de suicídio foi identificado em $16,4 \%$ dos moradores (PRISMMA, 2018, p. 49). O dano, nesse caso, transcende aquilo que as palavras do "juridiquês" e da linguagem própria do sistema penal é capaz 
de comportar. Vai além: requer a construção de novas identidades, novas memórias, um processo de reterritorialização (MIRANDA; RODRIGUES; ALMEIDA, 2017, p. 9), que jamais será finalizado a partir de uma eventual indenização que o Direito possa proporcionar.

Assim, enquanto autoridades e empresas firmam acordos, as vítimas seguem tendo suas demandas invisibilizadas, mesmo porque a resposta que a dogmática e o sistema penal conseguem dar é insuficiente. Este foi preparado para se voltar contra o pequeno delito, de caráter individualista e, majoritariamente, patrimonial, cometido pelo inimigo seletivamente construído como marginal. E mesmo nesse caso, a vítima fica silenciada, de fora de qualquer possibilidade de interpretação do ocorrido. Em realidade, os danos massivos e as dores das vítimas seguem invisíveis a esse sistema, o que se justifica, também, pelas peculiaridades daqueles que, costumeiramente, são os seus causadores: poderosos; pessoas jurídicas renomadas e de grande influência, que ditam a dinâmica estatal e política (BERNAL, 2017).

Dessa forma, enquanto o sistema penal demonstra sua falência - ou a consecução de seus objetivos reais - as dores seguem invisibilizadas, insuportáveis e irressarcíveis. É o que vemos em todos os casos citados acima, mesmo com todas as suas particularidades. Enquanto os procedimentos penais são executados pelas autoridades a quem a lei ofereceu um universo bastante limitado de disposições, os danos permanecem imunes a eventuais soluções que o sistema penal chame de justiça. O "crime", e seu correlato "pena", assim como definidos pelo sistema penal, são conceitos insuficientes para verdadeiramente ser possível lidar com pelo menos três questões: primeiro, e mais importante de tudo, com a dor das vítimas; segundo, e não menos importante, com o conflito gerado a partir da conduta danosa e que repercute em toda a comunidade; terceiro, com qualquer possibilidade preventiva que se volte ao futuro, posto que simultaneamente ao agir sempre voltado ao passado, quer dele apagar tudo o que possa funcionar como memória, apesar de ser justamente a memória o que pode garantir que o horror não volte a ocorrer.

\section{A DESLEgitimaçÃo do SIStema PENAL: OBJetivos DE- CLARADOS E OBJETIVOS REAIS}

De todos os ângulos a partir dos quais olhamos, é possível visualizar que o sistema penal e a lógica retributiva enquanto medida de justiça são postos 
em xeque. Até aqui falamos de uma dessas miradas possíveis: a completa incapacidade de enxergar e dimensionar o sofrimento da vítima pela redução do conflito aos limites da insuficiente fórmula crime-pena. A essa, podemos adicionar outra mirada: o descumprimento estrutural de todas as promessas por parte do sistema penal. Dentro de seus fins declarados, o Direito Penal apresenta-se como preventivo geral. Isso significa dizer que, teoricamente, a pena imposta se justificaria somente quando a punição fosse necessária e capaz de prevenir que potenciais criminosos viessem, eventualmente, a cometer essa mesma conduta praticada pelo autor do delito, ou, ainda, para que a comunidade viesse a ter certeza de que a lei atua e tem efeitos, devendo ser respeitada e obedecida. Ou seja, seria um reforço do sistema, a partir da mensagem de que a lei é válida, (SILVA; PASSETTI, 1997, p. 55).

Através dos estudos da criminologia crítica, disciplina que promoveu uma verdadeira ruptura de paradigma no estudo do desvio e do controle social, constata-se que a ideia de prevenção geral parte de dois pressupostos indemonstráveis: 1) de que todas as pessoas temem a lei da mesma maneira, pois a lei é a mesma para todas; 2) de que todas as pessoas possuem um consenso e consideram intoleráveis as condutas proibidas pelo direito penal.

O primeiro pressuposto é facilmente falseado: a criminalidade, como realidade social, não é uma entidade preconstituída em relação à atividade dos juízes, mas uma qualidade atribuída por estes últimos a determinados indivíduos. (BARATTA, 2011, p. 107). A criminalidade como dita e conhecida "não existe na natureza, mas é uma realidade construída socialmente através de processos de definição e de interação. Nesse sentido, a criminalidade é uma das "realidades sociais" (BARATTA, 2011, p. 108)". Isso implica que só existe crime quando, através de todos os filtros do sistema de justiça criminal alguém é efetivamente condenado em sentença final. Sabemos, porém, que essa construção é seletiva e prioriza determinados tipos de crimes para reagir - os crimes patrimoniais e de tráfico de drogas -; e determinados sujeitos para recrutar - homens e mulheres pobres, semianalfabetos, negros, periféricos (BRASIL, INFOPEN, 2018). A criminologia mostra que essa escoIha não é aleatória: perseguir os excluídos do mercado e do consumo é útil ao sistema capitalista (CHRISTIE, 1993); perseguir negros em uma sociedade racista, é útil à manutenção da ordem racial, e obedece a um projeto genocida de Estado (FLAUZINA, 2006; GOES, 2016; ALEXANDER, 2010). Ou seja, os objetivos reais do sistema penal, empiricamente constatáveis nas estatísticas 
de encarceramento, mostram a completa inversão em relação aos seus objetivos declarados (ANDRADE, 2003).

Se um homem branco, heterossexual, cisgênero e de classe média ou alta pretende praticar um crime, é óbvio que observará a atuação do sistema de justiça criminal real e não a previsão legal de sua conduta como crime. Sabendo que o sistema não é contra ele montado, é evidente que a noção de prevenção geral negativa cai completamente por terra. Como dizem Zaffaroni et al. (2003), a única prevenção que pode surgir daí é a aquela dirigida à criminalidade tosca: ninguém deixa de cometer crimes, apenas refina os seus métodos. Um bom exemplo são os grupos de WhatsApp e aplicativos para burlar as barreiras policiais de fiscalização de embriaguez ao volante. Se alguém efetivamente deixou de dirigir embriagado recentemente, provavelmente foi pela conscientização do risco causado a si próprio e aos próximos, e não por medo de uma pena.

A segunda premissa é também de fácil falseamento. Não há consenso sobre o que se consideram os crimes mais graves, e, principalmente, se houvesse, certamente não seriam aqueles previstos pela legislação penal como tais. Perguntamos, então, qual o bem jurídico leitoras e leitores consideram o mais importante: patrimônio ou vida? É muito provável que a resposta tenha sido a vida. A legislação penal, contudo, prevê penas mais graves para crimes contra o patrimônio do que para crimes contra a vida.

Se um grupo de quatro pessoas praticar o crime de extorsão mediante sequestro, ou seja, privar alguém da liberdade de ir e vir com o objetivo de obter um resgate em dinheiro, mesmo que não pratique nenhuma lesão corporal, a pena é de reclusão de 12 a 20 anos (art. 159, \$1 $1^{\circ}$, Código Penal) (BRASIL, 1940). Se esse mesmo grupo de pessoas, em outra situação, simplesmente matar alguém, a pena é de reclusão de 6 a 20 anos (art. 121 do Código Penal). Em princípio, parece óbvio que matar alguém é mais grave do que extorquir. Porém, nosso sistema econômico, que ao fim e ao cabo rege o direito penal, privilegia o dinheiro. Mais do que isso: qual é a cor e a classe social de quem são as prováveis vítimas de extorsão mediante sequestro? E do homicídio simples? Pelos dados do SUS, as pessoas que mais morrem vítimas de homicídios são jovens negros periféricos (WAISEFILS, 2016). São essas as maiores vítimas, e são as vítimas mais negadas, cujas mortes são inexpressivas nas páginas dos jornais e na indignação pública, principalmente se compararmos a casos em que jovens brancos são assassinados.

Outro exemplo dessa ausência de consenso é a tolerância existente so- 
cialmente a alguns tipos de crimes previstos pela legislação penal, como a sonegação fiscal. Neste caso específico, a criminalidade é até estimulada, mesmo que seus efeitos vulnerem direitos à saúde, à educação e a outros serviços públicos que dependem de arrecadação pelo Estado. Isso para não falar nos crimes ambientais, que nos afetam diretamente, e que geram pouca reação na sociedade.

Ou seja, confiar na validade da norma não previne o cometimento de crime ou mesmo a integração social: não existe uma concordância isenta de críticas entre a sociedade plural e o sistema penal. E mesmo as críticas que existem não podem ser interpretadas de forma alheia aos seus atravessamentos de classe, raça e gênero.

O crime não é um comportamento típico de uma minoria anormal, mas, sim, de todas as pessoas, mas que costuma ser colado a algumas pessoas pela construção seletiva e estigmatizante do próprio sistema penal, no qual um determinado grupo de indivíduos é estereotipado e definido como criminoso por aqueles que detêm o poder de criar e de aplicar a lei penal, mediante mecanismos seletivos, em que impera uma estrutura e funcionamento baseados no antagonismo dos grupos sociais (BARATTA, 2011, p. 112).

Indo além nessa discussão, é necessária a análise de outra questão. $O$ ponto de partida aqui é a maneira como o sistema penal - representado, por exemplo, pelas leis, pela polícia, pelo judiciário e pelo Ministério Público recebe o poder de ser o único legitimado para solucionar os conflitos entre as pessoas. Desse modo, tanto os discursos políticos, como os discursos do senso comum, invocam ser inadmissível seguir impune alguém que cometeu um delito, sendo necessário um castigo. Porém, o ponto central da discussão é de que esse sentimento de culpa, invocado para justificar o sistema penal, nada tem a ver com a existência de tal sistema (CELIS, HULSMAN, 1993, p. 69). Seguindo nessa linha, Louk Hulsman expõe que:

(...) é preciso afirmar com toda a convicção que não é a existência ou a inexistência do sistema penal que provoca tal sentimento, tanto quanto não é este sistema que poderá dar àquele que sofre, com sua consciência, a transformação interior de que possa necessitar. Nossas experiências profundas nada têm a ver com o sistema penal (CELIS, HULSMAN, 1993, p. 69).

Com isso, compreende-se que o sistema penal não pretende cessar o conflito existente na sociedade, e ainda menos erradicar os crimes, mas, isto sim: 
punir apenas uma pequena parcela daqueles que os cometem, escolhidos seletivamente conforme seu pertencimento de classe social, raça e gênero. Essa atitude, meramente repressiva e nada preventiva, indica que o sistema penal faz cair por terra o mito de que almeje evitar a ocorrência de novos delitos, ou mesmo reduzir a violência. O sistema penal produz mais violência do que a violência que pretende combater ou prevenir.

\section{A JUSTIÇA RETRIBUTIVA EM XEQUE}

O modelo de justiça criminal atual parte da premissa de que a busca da justiça se estabelece infligindo dor através da perda - perda de recursos, de liberdade, de identidade e até da vida. Assim, para existir justiça, deverá haver dor. O questionamento controverso dessa afirmação é que, para o sistema atual, quanto mais cruel for o método de punição, maior justiça haverá. O problema central da punição como resposta ao dano é que ela não consegue desempenhar as motivações do comportamento do indivíduo, apenas supre o comportamento advindo do dano através de reforços externos (ELLIOT, 2018, p. 74-75).

Em um contexto de democracia, as leis são aprovadas por representantes eleitos, e são executadas por órgãos administrativos governamentais. $\mathrm{O}$ trabalho da polícia é o de investigar e realizar prisões quando necessárias; os tribunais em virtude das leis processam acusações, e as agências correcionais são responsáveis pela efetivação das sentenças condenatórias a serem cumpridas em âmbito prisional ou comunitário. Esse sistema é construído a partir de uma rigidez e objetividade no controle da lei através do Estado para prosperar um processo justo a todos que o acionam (ELLIOT, 2018, p. 129).

Porém, esse controle do Estado acaba por negligenciar as relações humanas, deixando de lado as lesões e necessidades da vítima e do ofensor. $\mathrm{O}$ fenômeno do crime se torna maior do que o conceito de vida. O Estado-acusação torna-se autor da ação criminal, pois, segundo ele, os danos causados pelo crime foram contra a sociedade, e a vítima torna-se apenas um agente secundário, sendo cogitada para a apuração do caso. Portanto, o foco do sistema penal é ele próprio. Ele funciona para continuar funcionando, mesmo que de todas as funções que declara cumprir, nenhuma seja, na prática, cumprida. Para além do próprio sistema, entre os atores e atrizes presentes em um caso criminal, é o ofensor que efetivamente pode protagonizar o processo, apesar de, no sistema brasileiro, a acusação e mesmo o órgão jul- 
gador serem muito mais proeminentes do que a defesa. $O$ fato é que a parte mais frágil do fato sobre o qual se julga, que nesse caso é a vítima, acaba sendo desprezada.

O Estado, mediante a estrutura penal de punições por força da lei, sequestra das pessoas conflitantes, diretamente envolvidas no delito, a possibilidade de resolução. Porém, quando o problema é levado para as câmaras judiciais do Estado, o próprio aparato montado para reprimir e punir o criminoso retira os protagonistas do conflito e estipulam a eles um estereótipo de "delinquente" e a "vítima" (CELIS, HULSMAN, 1993, p. 82).

Ao serem retiradas do protagonismo, ofensores e vítimas são relegadas a uma condição submissa ao poder estatal. Ambas são silenciadas, sobretudo a vítima, e apenas servem como objeto de prova para condenar ou absolver. Nunca se coloca a tarefa de solucionar, de fato, os efeitos negativos do ato delituoso. A punição do "culpado" vai servir como "exemplo" para a sociedade e para ele próprio, justificando-se pela intimidação que isto deveria causar aos outros (prevenção geral) e pela inibição que deveria incutir no punido (prevenção especial) - efeitos que não consegue atingir, não existindo qualquer comprovação empírica (ZAFFARONI et al., 2003, p. 114-130). A "vítima", por sua vez, assume a posição de testemunha, e sua vontade, se não é totalmente desmerecida, é relegada completamente (DA SILVA; PASSETTI, 1997, p. 215).

A ideia de que para além da pena estatal só existiria violência instersubjetiva e dominação pela força é bastante curiosa, pois desconsidera, nas palavras de Giamberardino (2014, p. 91), "toda a complexidade das interações sociais, no que tange às práticas de controle social”, ao equiparar censura e pena. A mensagem que o sistema penal, tal como o conhecemos, transmite sobre punição é que não devem ser cometidas ofensas, pois são contra a lei e os indivíduos que a contrariarem, irão sofrer. Ao tratarmos de um delito, temos diversas partes envolvidas, e os órgãos do sistema de justiça criminal não são essas partes. Ou seja, naquela mensagem ignora-se que existem pessoas que sofrem pelo próprio delito, sobretudo quando falamos de condutas que vulneram as vidas e a integridade física e psicológica das vítimas. Ignora-se, em conjunto, o próprio desejo de não fazer sofrer ou mesmo de evitar a todo custo fazer sofrer. Vítima, ofensor, familiares da vítima, familiares do ofensor, amigos, colegas, pessoas da comunidade: se visibilizadas, a busca por reparação se dará através da atenção às partes envolvidas no conflito, buscando transmitir a mensagem de que não devem ser cometidas 
ofensas, pois elas prejudicam alguém, e que aqueles que causam danos precisam repará-los (ZEHR, 2008, p. 187).

As vítimas necessitam de quem as escute, que Ihes sejam oportunizados espaços para falarem sobre as suas histórias e os seus sentimentos. E, claro, que essas narrativas sejam tomadas em consideração quando da decisão sobre qual é o melhor caminho a seguir. Precisam de apoio e segurança para chegarem a vivenciar algo que se aproxime de justiça. Acima de tudo, as vítimas precisam contar a sua verdade (ZEHR, 2008, p. 108). A justiça é efetivada quando um indivíduo prejudica outrem e tem por obrigação a correção desse mal, pois os danos causados à vítima deveriam ser o problema central do conflito, já que o Estado não oferece a solução adequada para o tratamento das partes. Este é o problema central da justiça retributiva com a qual estamos acostumados: tudo se passa como se fosse impossível nos distanciarmos dessa lógica por um momento e pensarmos em alternativas que realmente possam trazer o consolo e o acolhimento necessário para as pessoas que sofrem com os danos causados.

O atendimento às vítimas tampouco deve se dar às custas de uma injustiça permanente sobre o condenado, como se as atitudes do indivíduo, mesmo após a punição, perdurassem indefinidamente e esse recebesse, para o resto da sua vida, a etiqueta de criminoso e merecesse o escárnio perpétuo da sociedade e do Estado (DA SILVA; PASSETTI, 1997, p. 150).

Um estudo bastante elucidativo disso é o realizado por Giamberardino (2014). Após a análise de 486 (quatrocentos e oitenta e seis) estudos psicossociais, entrevistas reduzidas a termo com acusados, vítimas e familiares em casos de crimes dolosos contra a vida, alguns dias antes da sessão de julgamento de cada caso no Foro Central da Comarca da Região Metropolitana de Curitiba, Paraná, o autor concluiu que existe uma diferença significativa entre os discursos de "desejar a condenação", "desejar uma resposta", "desejar que justiça seja feita”, e os discursos de "desejar que o réu sofra”, "desejar que seja infeliz". Ou seja, a ideia de responsabilização e reparação se distancia da ideia de vingança.

Dentre muitíssimas outras questões levantadas, o ponto central é que a necessidade de ressignificação e compreensão do ocorrido, seja em relação aos sujeitos vitimizados, seja aos criminalizados, não encontra vazão ou um espaço viável no sistema penal formal. Não há saída: caso se queira buscar construir uma perspectiva restaurativa de censura a partir da participação dos envolvidos, haverá que se operar com a ideia de reparação simbólica, não somente 
econômica, o que significa um tipo de reparação capaz de trazer de volta o sujeito, sua responsabilidade, uma forma de censura construída sob o sentido de alteridade. Reduzir o conceito de reparação à dimensão pecuniária implica o risco de se incorrer em um desvio de sentido que amesquinha e "privatiza" qualquer prática de mediação (GIAMBERARDINO, 2014, p. 94).

A pesquisa é central neste debate justamente porque nos ajuda a refletir sobre a distância abissal entre o que o sistema penal oferece e os possíveis desejos reais de resposta que desejam as vítimas e familiares no caso aqui estudado.

\section{O PAPEL DA MEMÓRIA PARA O FUTURO: RECONHECIMENTO E JUSTIÇA}

O conto de tradição oral para repassar informações e deixá-las vivas é experienciado desde as culturas primitivas. A importância de manter vivas as histórias dos povos para servir de experiência para as seguintes gerações sempre tiveram seu papel nas mais diferentes épocas, servindo sempre de conhecimento e prevenção de repetir os mesmos erros já superados no passado, conforme bem elucida Simson (2003):

[...] cultura é memória, pois é a cultura de uma sociedade que fornece os filtros através dos quais os indivíduos que nela vivem possam exercer o seu poder de seleção realizando as escolhas que determinam aquilo que será descartado e aquilo que precisa ser guardado ou retido pela memória porque, sendo operacional, poderá servir como experiência válida ou informação importante para decisões futuras.

Da análise da história política e social brasileira, nota-se o descaso da sociedade e do Estado quanto à memória das vítimas de grandes tragédias. Fazendo isso, ignora-se também que, se a memória fosse reconhecida e valorizada, poderia ser possibilitada também a sua não repetição, evitando assim imensas dores e sofrimentos que poderiam ser consequência do esquecimento.

A conduta de seguir em frente após acontecimentos atípicos, como o da boate Kiss, é dura e necessária. Entretanto, diferentemente do que parece, há diversos caminhos que podem ser escolhidos. Seguir em frente com a conduta de reconhecimento e memória do fato proporcionaria às vítimas 
um respeito maior às suas dores e levaria ao acolhimento de suas necessidades. Lamentavelmente, percebemos que, em geral, no Brasil prefere-se seguir em frente, simplesmente esquecendo, o que representa uma ofensa à memória das vítimas, bem como ao bem-estar de seus familiares.

Esse tipo de reação do Estado e da sociedade no Brasil não foi uma característica exclusiva do caso Kiss. Um excelente exemplo disso é o caso do crime ambiental ocorrido na cidade de Mariana, e já tratado anteriormente; outro exemplo significativo é o dos mortos e desaparecidos da Ditadura Militar brasileira. Neste último caso, a própria interpretação do Supremo Tribunal Federal a respeito da lei de anistia serviu como o ingrediente que faltava para se confundir perdão (forgiveness), com esquecimento (forgetfulness) (BUDÓ; MALVASIO; BONATTO, 2017). Embora sejam casos completamente diferentes uns dos outros, todos eles possuem alguns aspectos em comum, velhos conhecidos das teorias sobre os crimes dos poderosos e a justiça de transição: o esquecimento das vítimas (ausência de memória); a tentativa de negação das vítimas como vítimas (ausência de verdade); a ausência de reparação (ausência de justiça). De todos, o principal: a incapacidade e insuficiência do sistema penal para dar conta desses danos passados, de responsabilizar efetivamente as pessoas pelas suas condutas danosas, e de prevenir danos futuros.

A ausência de diálogo acerca desses acontecimentos e a intenção de esquecê-los, com o intuito de evitar sofrimento, acarreta a repetição dessas lamentáveis situações. O exemplo clássico das consequências do esquecimento é o desejo de algumas pessoas do retorno à Ditadura Militar. É o custo sentido de os horrores da censura à liberdade de expressão, da proibição do direito de reunião, da proibição de estabelecer críticas ao governo, e das consequências de torturas e mortes pelo simples fato de pensar diferente não terem sido publicamente o objeto de uma responsabilização individual e coletiva. Em outros países, como a Argentina, essa responsabilização ocorreu.

O incêndio ocorrido na boate Kiss, conforme narrado neste artigo, ocasionou na morte de 242 jovens, além de 648 feridos. A tragédia impactou o Brasil, sendo alvo de repercussão midiática, em tempo ininterrupto, durante o dia 27 de janeiro de 2013. No entanto, após cinco anos do referido acontecimento, qual é a repercussão que se tem verificado? Onde se encontram as pessoas vítimas dessa tragédia? Qual é a atenção efetivamente dedicada a elas? Que tipo de memória coletiva estamos construindo para efetivamente 
conseguirmos lidar com o sofrimento do passado carregando algo para o futuro?

Por intermédio desses questionamentos, entende-se a convergência existente nos três casos ora narrados. $O$ esquecimento das vítimas se faz notório, em virtude da inexistência de políticas públicas que as auxiliem, com exatidão, a superar e aceitar as suas tristes histórias.

Há cinco anos, foi criado o Acolhe Saúde para prestar atendimento aos familiares e vítimas da boate Kiss. Contudo, o Diário de Santa Maria (CERETTA, 2018) noticiou as denúncias em face do referido projeto, devido à dificuldade de os familiares obterem o tratamento necessário às suas saúdes psíquicas. Há três anos, os sobreviventes da boate também relataram a ineficácia dos atendimentos públicos disponibilizados (TRUDA, 2015).

Mais do que isso: há vítimas que, além de terem de lidar com essa triste situação fática, foram alvos de criminalização proposta pelos órgãos públicos que, em tese, deveriam auxiliá-las. Há vítimas, ainda, que foram e são discriminadas pela sociedade santa-mariense, devido à não compreensão empática de suas dores.

Se há consenso quanto ao controverso assunto, ele reside na certeza de que os sentimentos dos pais e das mães vítimas da Kiss deve ser respeitado. No entanto, essa tentativa de "andar para a frente" não pode ser feita de olhos fechados. Isso porque a cura, como na origem etimológica latina da palavra na língua portuguesa, vem do cuidado. Cuidado exige reconhecimento, e não esquecimento; ação, e não omissão. A violência distribuída seletivamente, única resposta que o sistema penal tem por tarefa dar, nada tem a ver com a cura. E é por isso que nos preocupamos em escrever este texto: para tentarmos contribuir com a possibilidade de superarmos as prisões que nos mantêm no caminho da conversão da dor da perda à dor da pena, como se isso efetivamente tivesse o condão de curar.

O reconhecimento das tragédias é imprescindível, a fim de que as vítimas sejam respeitadas e assistidas corretamente. Pensar coletivamente os impactos dessa tragédia na vida de cada santa-mariense, partilhar da necessidade de cura coletiva, de cuidado, escuta, acolhimento é o único caminho para que possam ser assumidas e exigidas medidas preventivas, visando ao conhecimento dos motivos geradores dessas situações atípicas. Concordamos com Daniela Arbex (2018, p. 227), no seu sensível relato sobre este caso: "a construção da memória do pior desastre provocado pelo homem na história recente do Brasil é necessária. Só assim o país poderá lidar de 
frente com as causas e as consequências de uma tragédia que envergonha pela matança e pela impunidade". Impunidade esta que é uma característica estrutural e inevitável do sistema penal, que, como já demonstramos, serve estruturalmente à gestão da pobreza e da racialidade e não à responsabilização e prevenção.

Questionar o que poderia - e deveria - ter sido feito para evitar o ocorrido não pode simplesmente passar com o decurso de mês ou ano. Afinal, embora tenhamos nos comovido com as vítimas da boate Kiss, assumimos condutas e exigimos que os poderes públicos e privados assumam condutas que objetivam a não repetição desses fatos?

A resposta que o sistema penal pode dar às vítimas da tragédia da Kiss não é uma resposta digna. Já não há mais como alimentarmos essa ilusão de dividirmos o mundo em bem e mal. Não há como reparar a dor. Não há forma de equiparar qualquer resposta jurídica à morte dos 242 jovens e outros tantos feridos. O sistema penal nunca chegará nas proporções dessa tragédia, pois é um mero acessório utilizado para repressão e punição seletiva e, quando o fato já ocorreu, resta a ele tão somente correr - ou talvez engatinhar - atrás do prejuízo.

\section{ROMPENDO OS GRILHÕES DA IMAGINAÇÃO}

A ideia de trazermos a gravura Pássaro, de Evandro Carlos Jardim, antes do texto, foi uma tentativa de expressarmos figurativamente aquilo que temos dificuldades de dizer em palavras. Uma tempestade de ideias de um grupo de onze pessoas profundamente emocionadas ao tentar escrever sobre uma dor que todas e todos carregamos como habitantes de Santa Maria levou à construção do argumento central deste trabalho: dor, sofrimento, invisibilidade, esquecimento, ineficácia, injustiça, incapacidade, insuficiência. No final, o que resultou de nossa reflexão: cuidado, acolhimento, reparação, escuta, diálogo, memória, reconstrução, responsabilização.

Um pouco dessa reflexão e um pouco do que nossa interpretação da gravura traz é sintetizada na fala de Giamberardino (2014, p. 98):

\footnotetext{
"Restauração", "restituição criativa”, mediação: a denominação não deve importar tanto, já que "nomes" muitas vezes podem trazer consigo vícios e experiências que não correspondem aos objetivos de fundo. O ponto central está na participação ativa e criativa dos sujeitos criminalizados e vitimizados, na criação de espaços viáveis de linguagem, de oportunidades de diálogo e mútua
} 
compreensão. É natural que prevaleça a utilização dos termos relativos às "práticas restaurativas" porque se trata, efetivamente, do mais consistente movimento, na atualidade, que caminha nessa direção. De todo modo, o termo não deve aprisionar e reduzir o potencial da proposta que está na base.

Como o pássaro aprisionado que se olha no espelho e se vê livre pela dificuldade de alcance da mirada à parte inferior onde estão os seus grilhões, seguimos também aprisionados à ideia de justiça que carrega consigo a aflição das pessoas responsáveis pelo dano. Essa prisão carrega várias consequências, nenhuma delas é positiva. Para ninguém.

Por mais que enxerguemos liberdade em determinadas soluções, a verdade é que não vemos, mas estamos presos. Por mais que a saída do direito penal pareça libertar, a dor nunca vai ser suprimida e estará sempre presa aos que perderam alguém, justamente porque o direito penal não cura, não libera. Aflige e aprisiona.

O reflexo no espelho, além de não representar a realidade, por ocultar o aprisionamento da imaginação à dureza da punição, também mostra o pássaro que se vê voando na direção oposta daquela para onde realmente está se dirigindo. A inversão do sentido no espelho corresponde à nossa “ilusão": enquanto voamos pensando estarmos nos dirigindo para a justiça e a libertação, estamos no caminho oposto. A punição nos leva à aflição e à invisibilidade. $O$ esquecimento nos leva à repetição, e não à reparação e à prevenção.

A parte inferior do quadro mostra, por outro lado, a imensidão daquilo que ainda não foi imaginado. Enquanto estamos presos às nossas ilusões, existe um céu infinito, misterioso, cheio de promessas de realidades que sequer podemos alcançar, cativos que somos das respostas historicamente construídas. O que vemos representa somente uma parte - embora distorcida - do todo. Duas estrelas brilham naquele céu. A memória dos 242 jovens que brilha esplendorosa, e deve continuar brilhando; e a esperança da libertação através de meios que ainda precisamos permitir à nossa imaginação nos levar.

\section{REFERÊNCIAS}

ALEXANDER, Michelle. A nova segregação: racismo e encarceramento em massa. São Paulo: Boitempo Editorial, 2017.

ANDRADE, Vera Regina Pereira de. A ilusão de segurança jurídica: do controle da violên- 
cia à violência do controle penal. Porto Alegre: Livraria do Advogado, 2003.

ARBEX, Daniela. Todo dia a mesma noite: a história não contada da boate Kiss. Rio de Janeiro: Intrínseca, 2018.

BARATTA, Alessandro. Criminologia Crítica e crítica do Direito Penal: introdução à sociologia do direito penal. Rio de Janeiro: Revan: Instituto Carioca de Criminologia, 6a ed., 2011.

BERNAL, Camilo Ernesto Sarmiento et al. Para além da criminologia. um debate epistemológico sobre o dano social, os crimes internacionais e os delitos dos mercados. Revista Brasileira de Direito, v. 13, n. 3, p. 40-79, 2017.

BEZERRA, Juliana. Desastre de Mariana. Toda Matéria. Disponível em: <https://www. todamateria.com.br/desastre-de-mariana/> Acesso em: 14 de novembro de 2018.

BRASIL. Decreto-Lei 2.848, de 07 de dezembro de 1940. Código Penal. Diário Oficial da União, Rio de Janeiro, 31 dez. 1940.

BRASIL, INFOPEN. Levantamento Nacional de Informações Penitenciárias. Brasília: Departamento Penitenciário Nacional - Ministério da Justiça e Segurança Pública, 2018. Disponível em: <http://depen.gov.br/DEPEN/depen/sisdepen/infopen-mulheres/infopenmuIheres_arte_07-03-18.pdf>Acesso em: 22 nov. 2018.

BUDÓ, Marília de Nardin; MALVASIO, Daniela Ruschel; BONATTO, Nahiara. Perdão ou esquecimento? O negacionismo no discurso do STF sobre a Lei de Anistia. Revista Meritum, v.12, p.119-145, 2017.

CARPINEJAR, Fabrício. A maior tragédia de nossas vidas. Carpinejar, 2013. Disponível em < http://carpinejar.blogspot.com/2013/01/a-maior-tragedia-de-nossas-vidas.html>. Acesso em: 22 nov. 2018.

CELIS, Jacqueline Bernart de; HULSMAN, Louk. Penas Perdidas: o sistema penal em questão. Niterói: Luam Editora Ltda, 1993.

CERETTA, Thays. Familiares das vítimas da Kiss reclamam da falta de atendimento. Diário de Santa Maria, 2018. Disponível em: <https://diariosm.com.br/not\%C3\%ADcias/sa\%C3\%BAde/familiares-das-v\%C3\%ADtimas-da-kiss-reclamam-da-falta-de-atendimento-1.2057514>. Acesso em: 14 nov. 2018.

CHRISTIE, Nils. A indústria do controle do crime: a caminho dos GULAGs em estilo ocidental. Tradução por Luis Leiria. Rio de Janeiro: Forense, 1998, 227p.

COLOGNESE, Mariângela Matarazzo Fanfa. As lamas da Samarco: um estudo sobre vitimização ambiental e dano estatal-corporativo a partir da perspectiva das vítimas. Passo Fundo: IMED, 2017. Dissertação (Mestrado) - Faculdade de Direito, IMED, Passo Fundo, 2017.

DA SILVA; Roberto B. Dias (org.); PASSETTI, Edson (org.). Conversações Abolicionistas: uma crítica do sistema penal e da sociedade punitiva. São Paulo: IBCCrim, 1997.

ELLIOTT, Elizabeth. Segurança e Cuidado: Justiça Restaurativa e Sociedades Saudáveis. São Paulo: Palas Athena; Brasília: ABRAMINJ, 2018.

FLAUZINA, Ana Luiza Pinheiro. Corpo negro caído no chão: o sistema penal e o projeto 
genocida do Estado brasileiro. Brasília: Universidade de Brasília, 2006, 145 p. Dissertação (Mestrado) - Curso de Mestrado em Direito, Universidade de Brasília, Brasília, 2006. Disponível em: <http://www.cddh.org.br/assets/docs/2006_AnaLuizaPinheiroFlauzina.pdf>. Acesso em: 20 nov. 2018.

GIAMBERARDINO, André Ribeiro. Crítica da pena e justiça restaurativa: a censura para além da punição. Florianópolis: Empório do Direito Editora, 2015, 266 p.

GOES, Luciano. A “tradução” de Lombroso na obra de Nina Rodrigues: o racismo como base estruturante da Criminologia brasileira. Rio de Janeiro: Editora Revan, 2016.

HILLYARD, Paddy; TOMBS, Steve. Más allá de la criminología. Crítica penal e poder. Barcelona, v. n. 4, p. 175-196, marzo, 2013.

MILANEZ B, Santos RSP, WANDERLEY LJM, MANSUR MS, PINTO RG, Gonçalves RJAF, et al. Antes fosse mais leve a carga: avaliação dos aspectos econômicos, políticos e sociais do desastre da Samarco/Vale/BHP em Mariana (MG). Disponível em <http://www.ufff. br/poemas/files/2014/07/PoEMAS-2015-Antes-fosse-mais-leve-a-carga-vers\%C3\%A30-final. pdf >. Acesso em: 22 nov. 2018.

MIRANDA, Maria Geralda; FRIEDE, Reis; RODRIGUES, Aline Cordeiro and ALMEIDA, Dafne Sampaio. Cadê a minha cidade, ou o impacto da tragédia da Samarco na vida dos moradores de Bento Rodrigues. Interações (Campo Grande) [online]. 2017, vol.18, n.2, pp.3-12. Disponível em: <http://dx.doi.org/10.20435/inter.v18i2.1410>. Acesso em: 22 nov. 2018.

MORRISON, Wayne. La imaginación criminológica bajo la globalización: recordando lo desaparecido. In: RIVERA, Iñaki (Coord..). Delitos de los Estados, de los Mercados y daño social. Barcelona: Anthropos, 2014. p. 223-252

NATALI, L. ; BUDÓ, Marília de Nardin . A sensory and visual approach for comprehending environmental victimization by asbestos industry in Casale Monferrato. European Journal of Criminology, v. 3, p. 1, 2018.

NEVES, Maila Castro Lourenço das. et al. PRISMMA: Pesquisa sobre a saúde mental das famílias atingidas pelo rompimento da barragem de Fundão em Mariana. Belo Horizonte: Corpus, 2018.

SILVEIRA, Alexandre Marques. Dano social estatal-corporativo e a vitimização ocasionada pela exposição ao amianto na cidade de Osasco-SP: um estudo criminológico a partir da representação das vítimas. Passo Fundo: IMED, 2018. Dissertação (Mestrado em Direito) - Faculdade Meridional, IMED, Passo Fundo, 2018.

SIMSON, Olga Rodrigues de Moraes. Memória, cultura e poder na sociedade do esquecimento. Augusto Guzzo Revista Acadêmica, São Paulo, n. 6, p. 14-18, may 2003. ISSN 2316-3852. Disponível em: <http://fics.edu.br/index.php/augusto_guzzo/article/view /57>. Acesso em: 15 nov. 2018. DOI: https://doi.org/10.22287/ag.voi6.57.

TRUDA, Felipe. Ainda em tratamento, sobreviventes da Kiss relatam falhas no atendimento. Dário de Santa Maria, 2015. Disponível em: <http://g1.globo.com/rs/rio-grande-do-sul/noticia/2015/01/ainda-em-tratamento-sobreviventes-da-kiss-relatam-falhas-no-atendimento.html>. Acesso em: 14 nov. 2018. 
WAISEFISZ, Julia Jacobo. Mapa da violência 2016: homicídios por armas de fogo no Brasil [internet]. Brasília: Flacso, 2016. Disponível em: <https://www.mapadaviolencia.org.br/ pdf2016/Mapa2016_armas_web.pdf>. Acesso em: 20 nov. 2018.

ZAFFARONI, Eugenio Raúl; BATISTA, Nilo; ALAGIA, Alejandro; SLOKAR, Alejandro. Direito Penal Brasileiro. v. I. Rio de Janeiro: Revan, 2003.

ZEHR, Howard. Trocando as lentes: um novo foco sobre o crime e a justiça. Tradução de Tônia Van Acker. - São Paulo: Palas Athena, 2008. 


\section{Ana Paula Frighetto Pereira}

Acadêmica de Direito da Universidade Federal de Santa Maria. Membra do grupo de pesquisa, ensino e extensão Poder, Controle e Dano Social da UFSM.

Endereço eletrônico: anafrighetto97@gmail.com.

\section{Isabel Foletto Curvello}

Acadêmica de Direito da Universidade Federal de Santa Maria. Membra do grupo de pesquisa, ensino e extensão Poder, Controle e Dano Social da UFSM.

Endereço eletrônico: isabelfoletto@gmail.com

\section{Leticia Blank Netto}

Acadêmica do curso de Direito da Faculdade de Direito de Santa Maria (FADISMA). Mediadora e facilitadora no Centro de Mediação e Práticas Restaurativas (CEMPRE). Membro do grupo de pesquisa, ensino e extensão Poder, Controle e Dano Social, da Universidade Federal de Santa Maria (UFSM). Rio Grande do Sul.

Endereço Eletrônico: leticiablank@hotmail.com

\section{Marília de Nardin Budó}

Professora no curso de Direito da UFSM. Doutora em direito pela UFPR. Estágio pós-doutoral em criminologia concluído pela Universidade de Barcelona. Mestre em direito pela UFSC. Graduada em direito e em jornalismo pela UFSM. Coordenadora do grupo de pesquisa, ensino e extensão Poder, Controle e Dano Social da UFSM.

Endereço Eletrônico: mariliadb@yahoo.com.br

\section{Mateus Rech Graciano dos Santos}

Acadêmico do curso de Direito da Faculdade de Direito de Santa Maria. Membro do grupo de pesquisa, ensino e extensão Poder, Controle e Dano Social da UFSM. Membro do Nú- 
cleo de Segurança Cidadã (NUSEC/FADISMA).

Endereço eletrônico: mateusg.rech@hotmail.com

\section{Mical Alexia Abrantes Moraes}

Acadêmica de Direito da Universidade Federal de Santa Maria. Membra do Núcleo de Direito, Marxismo e Meio Ambiente (NUDMARX) e do grupo de pesquisa, ensino e extensão Poder, Controle e Dano Social da UFSM.

Endereço eletrônico: micalalexia@gmail.com

\section{Pablo Domingues de Mello}

Acadêmico de Direito da Universidade Federal de Santa Maria. Membro do grupo de pesquisa, ensino e extensão Poder, Controle e Dano Social da UFSM. Membro do Observatório Permanente de Discurso de Ódio do Núcleo de Direito Informacional da UFSM (NUDI - UFSM). Membro do Clube de Direito Internacional da UFSM.

Endereço eletrônico: pablodominguesmello@gmail.com

\section{Priscilla Silva}

Acadêmica de Direito da Universidade Federal de Santa Maria. Membra do grupo de pesquisa, ensino e extensão Poder, Controle e Dano Social da UFSM.

Endereço eletrônico: priscillasilva1095@gmail.com

\section{Rafaela Bogado Melchiors}

Acadêmica de Direito da Universidade Franciscana e bolsista PIBIC/CNPq. Membra do grupo de pesquisa, ensino e extensão Poder, Controle e Dano Social da UFSM. Endereço eletrônico:rafaelamelchiors@hotmail.com

\section{Thais Bonato Gomes}

Especialista em Direito e Processo do Trabalho pela Universidade Franciscana (UFN), Santa Maria/RS, graduada em Direi- 
to pela mesma instituição. Advogada. Membra do grupo de pesquisa, ensino e extensão Poder, Controle e Dano Social da UFSM.

Endereço eletrônico: thaisbonatog@gmail.com

\section{Yngrid Algarve Vizzotto}

Acadêmica de Direito da Universidade Federal de Santa Maria. Membra do grupo de ensino, pesquisa e extensão Poder, Controle e Dano Social da UFSM.

Endereço eletrônico: yngridalgarve@hotmail.com 